\title{
Natural gas back in favour with US power companies
}

Electric utilities in the United States are quietly shifting their sights from coal to natural gas as the lower-risk fuel while they wait for the nation's carbon policy to be decided.

Recent proposals to build coal-fired power plants have been sunk after hitting a wall of public and political opposition in Texas, Kansas and Florida. Investors and lenders - including some of Wall Street's leading investment banks — are increasingly worried about the imposition of greenhouse-gas regulations in the coming years. Add to this the rising prices of materials such as steel and concrete, which are driving up construction costs, and coal no longer looks like the safe investment it did just a few years ago.

This new calculus hit home in 2007, when plans for more than 50 coal-fired power plants were cancelled, according to consulting firm Global Energy Decisions, based in Boulder, Colorado. In their place, experts say, utilities are turning to natural gas as a quicker, cheaper and lower-emission alternative to meet growing demand while lawmakers sort out the nation's carbon policy.

"Over the past year to two years there's been this 180-degree turn from concerns about dependence on natural gas to concerns about climate change," says Larry Makovich, an energy analyst and senior power adviser at Cambridge Energy Research Associates in Massachusetts. "The US power sector has started to move back towards natural gas in a very substantial way."

Cleaner-burning natural gas became the fuel of choice for new electricity generation in the 1990s, but increased demand coupled with peaking production in many US gas fields caused prices to spike in 2002. At about US $\$ 8$ per million British thermal units, today's prices are more than triple the average throughout the 1990s. Building more natural gas plants could drive prices even higher - and make the nation that much more dependent on imports, which are already on the rise. Coal currently provides almost half of the nation's electricity,
"There's been this

180-degree turn from concerns about dependence on natural gas to concerns about climate change."
But given the major up-front costs and a lack of certainty about long-term economics owing to impending climate regulation, neither coal nor nuclear power look terribly attractive from an economic standpoint at the moment, says Revis James, a researcher at the Electric Power

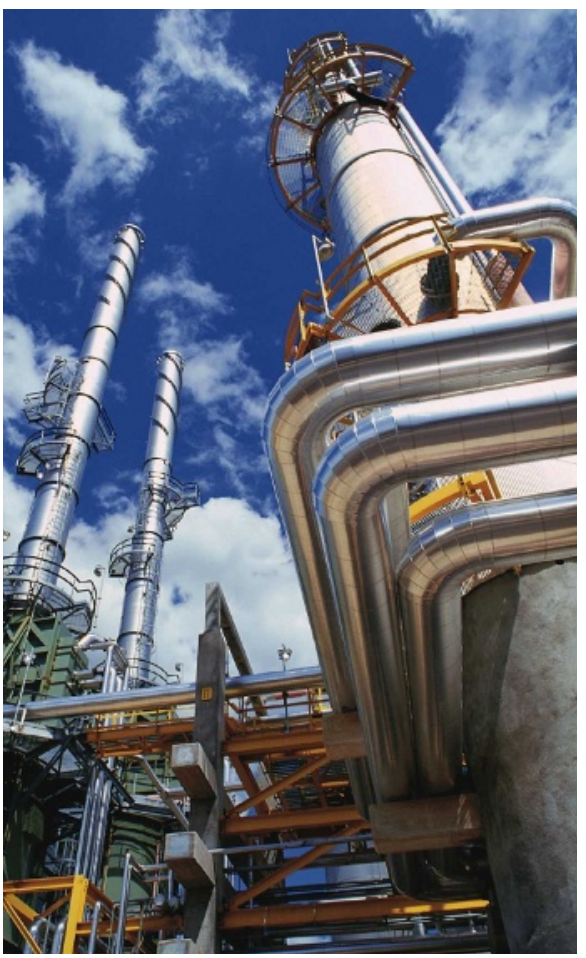

Natural gas produces fewer emissions than coal, but supplies are shrinking and its cost is rising.

Research Institute in Washington DC. "In the long run, coal and nuclear will have to play a pretty big role," he says. "But for now, gas seems to be the default."

Dan Riedinger, a spokesman for the Edison Electric Institute, the industry's main trade association, acknowledges the trend towards natural gas but suggests that the expansion of coal-fired power is unlikely to halt. The resurgence of coal several years ago was "greatly exagand is one of the few domestic energy resources that remains in abundance. Utilities also see coal, along with nuclear power and natural gas, as a critical source of constant 'base-load' power. gerated", he says, "and I think there is certainly some hyperbole with regard to the pendulum swinging in the other direction".

Jeff Tollefson 